\title{
A Review on Flexible and Transparent Energy Storage System
}

\author{
Jie Li, Qianqian Jiang *, Nannan Yuan and Jianguo Tang * \\ Institute of Hybrid Materials, The National Base of International Scientific and Technological Cooperation on \\ Hybrid Materials, The National Base of Polymer Hybrid Materials in the Programme of Introducing Talents \\ Discipline to Universities, College of Materials Science and Engineering, The Growing Base for State Key \\ Laboratory, Qingdao University, Qingdao 266071, China; lijie19921113@163.com (J.L.); \\ lynn051227@163.com (N.Y.) \\ * Correspondence: kaiqian2008@qdu.edu.cn (Q.J.); jtang951@163.com (J.T.); Tel.: +86-178-5323-7657 (Q.J.)
}

Received: 10 September 2018; Accepted: 16 October 2018; Published: 14 November 2018

\begin{abstract}
Due to the broad application prospect, flexible and transparent electronic device has been widely used in portable wearable devices, energy storage smart window and other fields, which owns many advantages such as portable, foldable, small-quality, low-cost, good transparency, high performance and so on. All these electronic devices are inseparable from the support of energy storage device. Energy storage device, like lithium-ion battery and super capacitor, also require strict flexibility and transparency as the energy supply equipment of electronic devices. Here, we demonstrate the development and applications of flexible and transparent lithium-ion battery and super capacitor. In particular, carbon nanomaterials are widely used in flexible and transparent electronic device, due to their excellent optical and electrical properties and good mechanical properties. For example, carbon nanotubes with high electrical conductivity and low density have been widely reported by researchers. Otherwise, graphene as an emerging two-dimensional material with electrical conductivity and carrier mobility attracts comparatively more attention than that of other carbon nanomaterials. Substantial effort has been put on the research for graphene-based energy storage system by researchers from all over the world. But, there is still a long way to accomplish this goal of improving the performance for stretchable and transparent electronic device due to the existing technical conditions.
\end{abstract}

Keywords: flexible; transparent; energy storage system; lithium-ion battery; super capacitor

\section{Introduction}

With intensification of energy crisis, more and more countries and people are paying attention to the collection and application of renewable energy, such as wind energy, water energy and solar energy. Meanwhile, the exploration of stable new energy storage system has got increasing attention of scientific researchers. In order to find appropriate materials owing advantages with low cost, clean, flexible, transparent and high performance, or to design new structure to utilize this new energy. Lithium-ion battery [1-6] and super capacitor [7-11], as green energy, have advantages of large energy density, high power density, long service life, no environmental pollution and so on. So, a large amount of research on lithium-ion battery and super capacitor has been reported. In this paper, we will introduce the research and development of lithium-ion battery and super capacitor in recent years. Most of the previous energy storage devices are rigid which cannot meet today's stringent requirements, because electrode materials are easy to be separated from the collector. Then influence electrochemical performance, even lead to short circuit and cause serious safety problems and great waste in bending and folding. Therefore, flexible and transparent energy storage system has been urgently used for portable wearable devices, light-emitting diode [12], transistor [13], energy storage smart window [7], gas sensor [14] and so on. 
Though the application of the flexible and transparent energy storage device like lithium-ion battery and super capacitor is an inevitable trend of the development, it still faces many challenges compared to the rigid devices. For example, a part of flexible energy storage device requires expensive raw materials. Even, some transparent devices have poor electrochemical performance, like short endurance. Moreover, it is hard to integrate flexibility and transparency together. Hence, it still has a long way to go for scientific research workers to fabricate new energy storage device integrated flexibility, transparency and with high performance.

In order to obtain excellent performance, extensive research especially for electrode has been studied. Due to excellent mechanical and electrical properties, nanostructure samples such as nanotube/nanowire, nanosheet and nanopaper have great potential to be fabricated as the flexible and transparent electrode $[15,16]$. For example, Ag nanowire networks with wavy configurations have been demonstrated. That networks show great potential in electromechanical stability based on transferring NW networks into a variety of substrates. Besides, the transmittance of Ag NW networks electrode reaches $80.1 \%$, which means Ag NW networks are suitable for flexible and transparent device [17]. Nanopaper, a freestanding paper-like conductive film, is also used frequently because of unique features of superior integrated flexibility and transparency. Bin Yao and co-workers demonstrate molybdenum trioxide nanopaper as the ultrathin transparent paper electrode [18]. And this electrode exhibits excellent performance in both lithium-ion battery and super capacitor, indicating the great potential of this nanopaper electrode in flexible and transparent energy storage devices. Though the flexible or transparent device has been greatly developed, it still has a long way to develop non-polluted, high powered and low-cost new type energy storage system due to the limitation in the integration of flexibility and transparency.

\section{Lithium-Ion Battery}

\subsection{Flexible Lithium-Ion Battery}

Nowadays, our daily life is changed a lot, due to the development of electronic device but all of this equipment cannot be boot up without energy storage device. Lithium-ion battery as the most important one both in academia and industry occupies the vast majority of electronic device market [19-21]. It consists of cathode, anode, current collector, separator and packaging material. Lithium-ion battery, which was studied in the 80s of last century, has the advantages of high energy density, high output power, long cycle life, wide working range and relatively friendly to environment. Although the traditional lithium ion battery has many advantages, the disadvantages cannot be ignored. It is not only bulky but also unfolding. Even when the volume change is too large, it will lead to short circuit between cathode and anode, resulting in serious safety problems. Therefore, in order to adapt to the development of the next generation of flexible electronic equipment, the direction of the development of lithium ion batteries should also be developed in the direction of flexible and folding [22-26]. The usual method to fabricate flexible lithium-ion batteries is to coat active materials to flexible substrates. But, active material is easily separates from substrate by this method. In order to avoid this phenomenon, a one-step spraying method is adopt to prepare the embedded electrode materials within ultrathin carbon nanotube network for the flexible thin film lithium-ion battery, which can greatly improve the reversibility [1]. Owing to the shortened $\mathrm{Li}^{+}$diffusion distance, sufficient conductivity, high contact surface area and excellent structure stability of the nanotube arrays, the self-supported $\mathrm{Li}_{4} \mathrm{Ti}_{5} \mathrm{O}_{12}-\mathrm{C}$ electrodes are expected to open up new opportunities to flexible electronic devices [27]. With the further research, various novel electrode nanostructures are proposed. A new-type integrated design of electrode is reported. Liangbing Hu and co-workers first use paper as separator and carbon nanotube thin films as both anode and cathode current collectors. Then, the lithium-ion battery is integrated into single sheet of paper by a simple lamination method. They find, the paper battery can continuously brighten the red LED for $10 \mathrm{~min}$ without fading (in Figure 1a). Even after bending the device manually to $6 \mathrm{~mm} 50$ times, no paper battery failure is observed, suggesting excellent flexibility (Figure $1 \mathrm{~b}$ ). The first cycle voltage profile of lithium ion battery 
can be seen in Figure 1c. As shown in Figure 1d, after the first cycle, the coulombic efficiency is 94-97\%. After 20 cycles, the discharge retention is 93\%. The battery also displays good self-discharge performance in the inset of Figure 1d, which is indispensable for practical application [23]. In addition, graphene as a wonderful electrode material can be used in flexibly lithium-ion battery. It can composite with $\mathrm{Bi}_{2} \mathrm{Se}_{3}$ to form $\mathrm{Bi}_{2} \mathrm{Se}_{3} /$ Graphene (BSG) composite paper. Compared with the pure $\mathrm{Bi}_{2} \mathrm{Se}_{3}$ nanosheets, this novel flexible BSG paper has a high reversible capacity of $203 \mathrm{mAh} \mathrm{g}^{-1}$ after 100 cycles at $50 \mathrm{Ma} \mathrm{g}^{-1}$, benefiting from graphene with outstanding electrical conductivity and excellent electrochemical discharge/charger stability [28]. The reasonable design of the next generation of activated energy storage graphene materials is demonstrated. The researchers found that three-dimensional graphene used for lithium-ion battery showed unexpected excellent performance. $\mathrm{Na} \mathrm{Li}$ and co-workers fabricate a flexible graphene foam electrode lithium-ion battery with ultrafast charge and discharge rates [29]. The battery has ultrafast charge and discharge rates, due to graphene foam with excellent electrical conductivity and pore structure to enable rapid electron and ion transport, which indicates that 3D graphene, is available to be applied in a thin, lightweight and flexible lithium-ion battery with high-rate performance and energy density. 3D nitrogen-doped graphene foam with encapsulated germanium/nitrogen-doped graphene yolk-shell nanoarchitecture is fabricated, which has a high capacity values about $1220 \mathrm{mAh} \mathrm{g}^{-1}$, excellent cycling capability of over $96 \%$ reversible capacity retention after 1000 cycles and ultra-high rate capability due to the yolk-shell structure can effectively relieve volume expansion during the charge and discharge [30]. Moreover, it provides an effective thinking for those materials with a large expansion coefficient.

More significantly, the flexible lithium-ion battery full cell has been studied. Zongnan Deng and co-workers construct 3D ordered microporous $\mathrm{MoS}_{2} @ \mathrm{C}$ nanostructure which is further fabricated as the flexible full cell. And the full cell shows outstanding area capacity and excellent capacity retention. The initial capacity of battery is $2.661 \mathrm{mAh} \mathrm{cm}^{-2}$ at $0.2 \mathrm{~mA} \mathrm{~cm}^{-2}$ current densities. The battery holds wonderful stability capacity retention after 20 cycles with the value of $1.681 \mathrm{mAh} \mathrm{cm}^{-2}$ at $5 \mathrm{~mA} \mathrm{~cm}^{-2}$ current densities, even with no capacity decay after another100 cycles. To test the stretchability, they demonstrated a stretchable LIB full cell. The brightness of the beginning is consistent with the brightness after the first bending and 300 bending cycles and there is no obvious change in brightness which illustrates the superior stability of the cell [31]. Through the above discuss, we can find that flexible lithium-ion battery has broad prospects in bendable smart phone, wearable electronics and medical devices, due to their special structures. So, it needs more attention to find suitable materials and design structure to improve flexibility, cycling stability and capacitance.
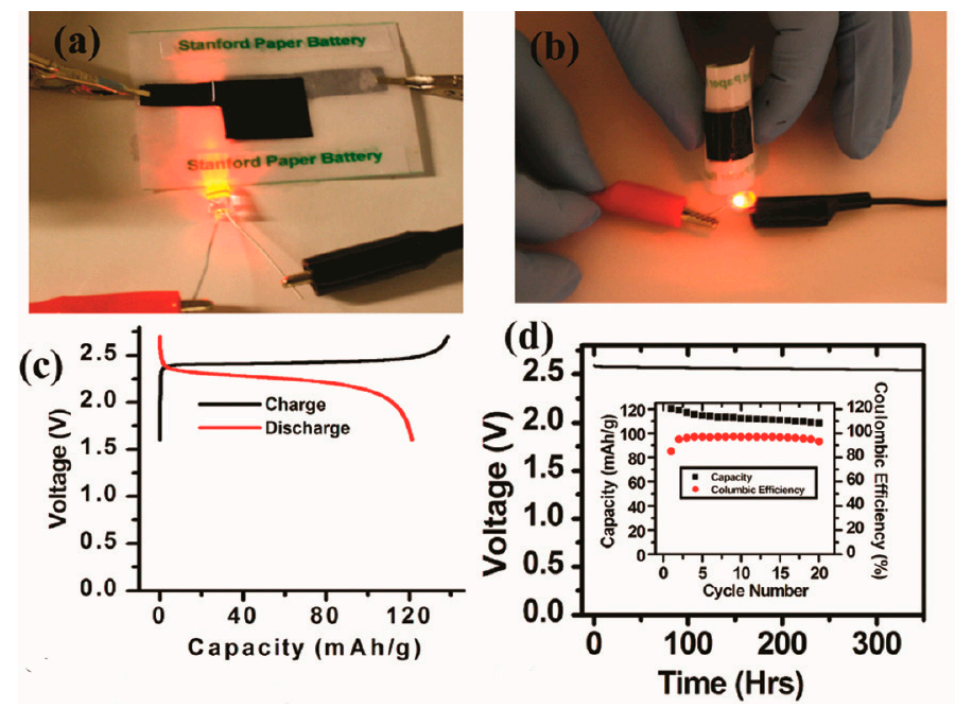

Figure 1. (a) Lithium-ion paper battery lighting red LED. (b) Flexible Lithium-ion paper batteries light an LED device. (c) Galvanostatic charging and discharging curves of paper battery. (d) Self-discharge behavior of a full cell after being charged to 2.6 V [23]. Copyright 2010, American Chemical Society. 


\subsection{Transparent Lithium-Ion Battery}

With the development of all transparent concept electronic devices, transparent electronic appears substantial applications for display, portable electronic device and solar cell [32]. For example, the concept of fully transparent cell phone has attracted great attention. Transparent screen also has rapid development. However, the key to develop transparent cell phone is to overcome the problem of full transparent battery. However, the research and development of transparent lithium-ion batteries is still at an initial stage. The typical method to make transparent device is to decrease the thickness of the battery, which is not suitable for the new type of battery.

It is well known that typical electrodes are always thick and most of them use the materials absorbing light, which will seriously affect the transparency of batteries. Hence, transparent lithium-ion battery faces a series of challenges. Francisco Martin and co-workers firstly describe the transparent electrode made from man-sized $\mathrm{LiFeO}_{2}$ directly grown on an indium tin oxide (ITO) substrate. The capacity of transparent electrode achieves $160 \mathrm{Ah} \mathrm{kg}^{-1}$ with capacity retention near to $98 \%$ [33]. And this is of great significance for the development of transparent batteries. But, such electrode has many limitations in the practical appliance of transparent batteries. For example, the transparency cannot meet the requirements of transparent devices. A novel grid-structured electrode breaks the limitations of changing the thickness of the film to improve transparency by aligning multiple electrodes together to increase amount of energy stored [34,35]. Yuan Yang and co-workers adopt a previously undescribed strategy of electrodes. A unique microfluidics-assisted method to pattern battery materials: (1) Transfer grid patterns from silicon mold to PDMS; (2) Evaporate gold current collector onto the PDMS substrate; (3) Fill in battery electrode materials by a microfluidics-assisted method and (4) Peel off gold film on top of the PDMS substrate. By this method, the transparency of battery is $78 \%, 60 \%$ and $30 \%$, respectively, corresponding to the energy density of 5,10 and $20 \mathrm{Wh}^{-1}$ [35]. Certainly, high transparency device manufactured by this method require very high accuracy, which limits the more practical applications.

A fully integrated transparent battery obtained from a the rapid and controllable spin-spray layer-by-layer deposition is demonstrated [36]. These facile spin-spray layer-by-layer deposition films have a $>87 \%$ transmittance, with $\sim 2 \mathrm{~nm} /$ bilayer precision deposited on a transparent substrate. The capacity of full cell has an excellent stable over 100 cycles, with a capacity of $5 \mu \mathrm{Ah} \mathrm{cm}^{-2}$. However, the limitation of the battery is inevitable that the full cell battery potential is lower than the initial cathode lithiation about $1 \mathrm{~V}$. Though this battery exist limitation for the applications, the design direction of the new transparent battery is put forward. It provides a technology suitable for industrial production of transparent electrodes. Further, it can realize a potentially fully integrated transparent device. Therefore, the transparent lithium ion battery generated by this SSNL technology is an important topic in the future research of lithium ion batteries.

\section{Super Capacitor}

\subsection{Flexible Super Capacitor}

Super capacitor, called electrochemical capacitor or ultracapacitor, has gained increasing concerning. Compared with traditional capacitor, it has larger capacity, specific energy, capacity density, wider working temperature range and longer service life. Compared with batteries, it has higher specific power and environment friendly [37]. With the development of electronic device demands, super capacitor must be flexible and foldable, which will be a trend of the future development direction [38-41].

In general, super capacitor includes four components (electrode, separator, current collector and electrolyte) and each of components must be flexible. Only in that way, can the super capacitor meet the application requirements of flexibility. The typical and mature flexible super capacitor is a kind of super capacitor with two-dimensional planar structure. Carbon-based materials, mainly included carbon nanotube [42] and graphene [43-45], are the most widely used electrode materials in flexible 
super capacitor [10]. Compact carbon nanotube composites used as electrodes of super capacitor show high specific capacitance of $13.16 \mathrm{~F} \mathrm{~cm}^{-3}$ and excellent cycling stability even after 10,000 cycling. More importantly, the super capacitor displays outstanding stretch ability as high as $240 \%$ [42]. Papers are not only flexible but also can be readily integrated with carbon nanotubes. So, it is a great candidate for substrates of flexible super capacitor. For example, a flexible super capacitor fabricated with bacterial nanocellulose papers, carbon nanotubes and triblock-copolymer ion gels is reported. The super capacitors showed high tolerance against. As shown in Figure 2, it can highly retain through 200 bending cycles to a radius of $3 \mathrm{~mm}$ [46]. Besides, carbon nanotubes can also be combined with textiles. By coat single-walled carbon nanotubes (SWNTs) on cellulose and polyester fibers, we are taking a big step forward to wearable devices [47]. However, compared with other carbon-based materials, the specific surface area of carbon nanotube is too small, which hinder the energy density and power density of super capacitor. Due to the good electrical conductivity and large specific surface area, graphene has attracted much attention of researchers. 2D ultrathin $\mathrm{MnO}_{2}$ /graphene nanostructure exhibits excellent electrochemical performance. The specific capacitance reaches $267 \mathrm{~F} \mathrm{~g}^{-1}$ at a current density of $0.2 \mathrm{~A} \mathrm{~g}^{-1}$ and the capacitance retention rate remains $92 \%$ after 7000 charge/discharge cycles. Even after repeated folding, the capacitance keeps $>90 \%$ [43]. The rational design of planar super capacitor can make a great contribution to the future development of high performance, flexible energy storage device.

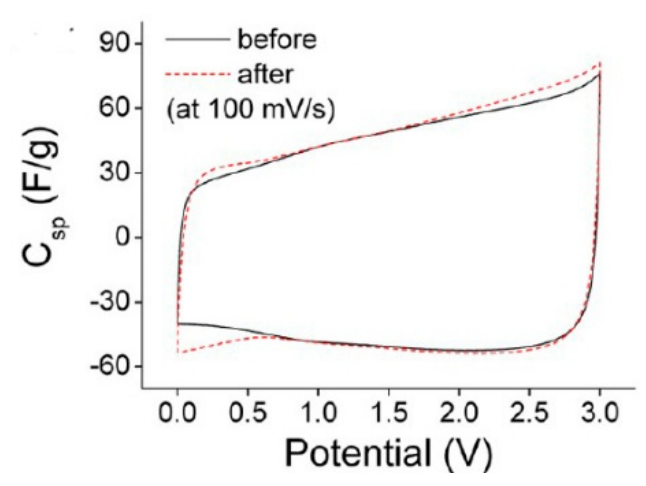

Figure 2. Cyclic voltammetry curves measured before and after 200 bending cycles [46]. Copyright 2012, American Chemical Society.

On the other hand, polyaniline (PANI) is a very good super capacitor material, because it is easy to handle synthesis and has high specific capacitance and good environmental stability. So, the construction of a graphene-PANI composite electrode has been an attractive topic. Huai-Ping Cong and colleagues find a particular and facile manufacturing method on a large-scale free-standing graphene paper as shown in Figure 3. The photograph of graphene paper peeled off from Teflon substrate is shown in Figure 3a. Specific preparation process of graphene-PANI paper is displayed in Figure 3b. Firstly, the graphene paper formed by a one-step reduction-assembly method is peeled off from the Teflon substrate and then graphene paper is electro polymerized with the PANI nanorods to make the PANI nanorods uniformly distribute on the surface and interior of the graphene paper. Flexible graphene-PANI paper prepared by this method has the advantages of low cost, easy processability into devices and excellent energy storage performance [38]. Certainly, with the current technical backgrounds, carbon nanotube and graphene materials used in electrode are not very mature yet in industry. To meet the requirements of the micro and wearable electronic devices, a new type of super capacitor, one-dimensional fiber structure has been rapidly developed. Because of its small size in volume and light in weight, this kind of super capacitor not only has good flexibility but also has high portability [48], which makes it have broad application prospect in flexible super capacitor. 

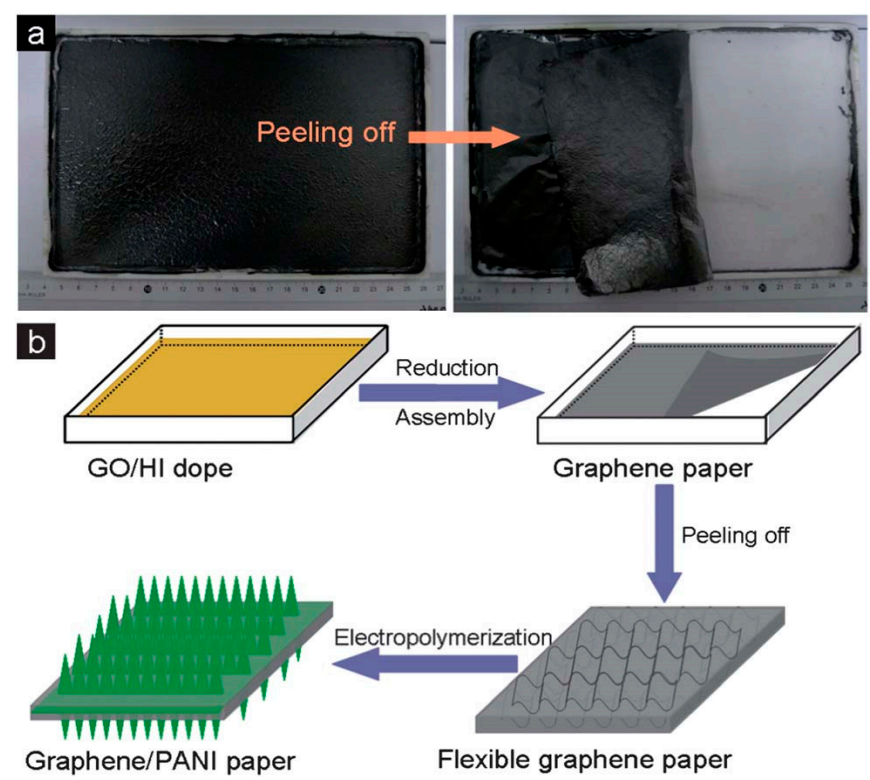

Figure 3. Schematic illustration of large-scale formation process graphene paper. (a) Peeling-off graphene paper with the size of $22 \times 16 \mathrm{cmfrom}$ a Teflon substrate. (b) Formation process of graphene-PANI paper [38]. Copyright 2013, the Royal Society of Chemistry.

\subsection{Transparent Super Capacitor}

Super capacitor becomes more important recently owing to their high energy density, power density and great potential to act as integrated power sources for displays and smart windows. However, transparent super capacitor device with both good transparency and high specific capacitance is hardly reported, which poses a great challenge to develop high transparent super capacitor [49].

As an important part of super capacitors, any small progress in electrode can always arouse great interest of researchers. A transparent electrode material is made of ultrathin single wall carbon nanotube film. This ultrathin single-walled carbon nanotube film got high transparence approaching to $90 \%$ with decrease of the film thickness [50]. Besides, graphene has been often adopted on account of the unique planar structure, excellent electrical conductivity, large specific surface area and high optical transmittance. Transparent hybrid film electrode composed of reduced graphene oxide (RG-O) and $\mathrm{Cu}$ nanowires (NWs) not only has great transparency but also can improve electrical conductivity, oxidation resistance, substrate adhesion and stability of super capacitor in harsh environments [51].

Besides, Jorge Rodriguez-Moreno and co-workers introduce a semi-transparent super capacitor. The super capacitor has a novel architecture and hybrid electrode material with improved capacitive performance. And the schematic diagram of the vertically aligned ZnO@CuS@PEDOTcore@shellnanorods arrays decorated with $\mathrm{MnO}_{2}$ nanoparticles is demonstrated in Figure 4. The formation process of ZnO@CuS@PEDOTcore@shellnanorods arrays includes electrochemical growth of vertically aligned ZnO NRs array as nanostructure collector, CuS nanocrystal line layer grown by spray pyrolysis, the poly (3,4-ethylene-dioxythiophene) (PEDOT) electropolymerization and formation of $\mathrm{MnO}_{2} \mathrm{NPs}$ by redox exchange. This hybrid nanostructure can increase the transmittance of light. It has a high aspect ratio and high surface area, which makes the super capacitor superior transparency and excellent electrochemical performance and solves a big problem of transparent super capacitors [49]. Although the researchers involve a lot of effort on the transparent super capacitor, due to the limitations of current science and technology, the application of high performance transparent super capacitor has been hindered, which inspires us to put more enthusiasm on research of transparent super capacitor in the future. 


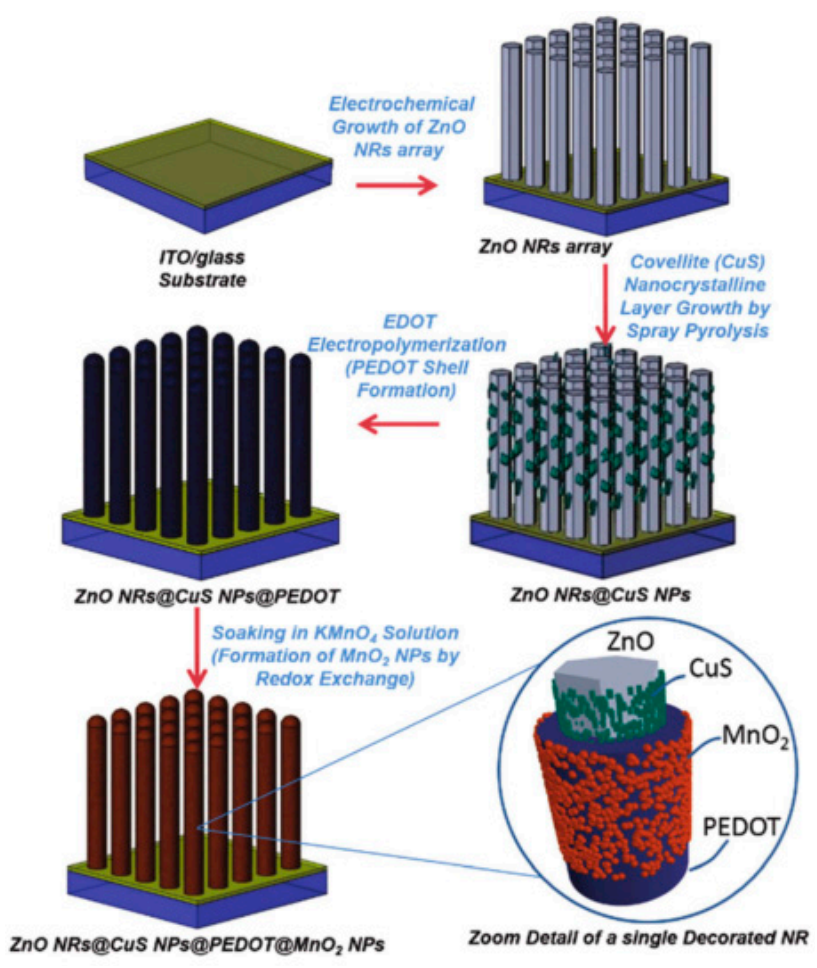

Figure 4. Schematic illustration of formation process of ZnONRs@CuS@PEDOT@MnO $\mathrm{M}_{2}$ hybrid nanostructured electrode [49]. Copyright 2014, the Royal Society of Chemistry.

\subsection{Flexible and Transparent Super Capacitor}

As well known, the integrated advantages of high performance, flexibility and transparency super capacitor is widely studied [52-57]. Nevertheless, most existing super capacitors cannot be transparent and scalable at the same time, or it has these two characteristics but the electrochemical performance is not so good. Carbon nanomaterials are well suitable for flexible and transparent electronic devices. It is benefiting from their unique advantages, such as electronic and optical properties, structures, processability and compatibility [58-61]. One of application is the carbon nanotube based flexible and transparent layer $[62,63]$. Due to the high conductivity and mechanical property, carbon nanotube electrode has been reported frequently in the literature [64,65]. An important way to obtain flexible and transparent super capacitor with high performance is by aligning carbon nanotubes $[64,66,67]$. The aligned transparent and stretchable CNT film and their fabrication process are shown in Figure 5a. The assembled super capacitor in the parallel and cross configurations is in Figure 5b-e are photographs of a super capacitor before and after stretching [66]. The sample aligned with carbon nanotubes shows superior electrochemical performances than that of randomly dispersed carbon nanotube composite films, which makes its own great potential in application of novel flexible and transparent super capacitor. It can be seen that the material with higher alignment will have superior performance and also has higher transparency, high specific capacitance and longer life. It provides a new horizon for future transparent and flexible super capacitor. That is supplying new methods to improve material's performance by precisely adjusting the structure. 


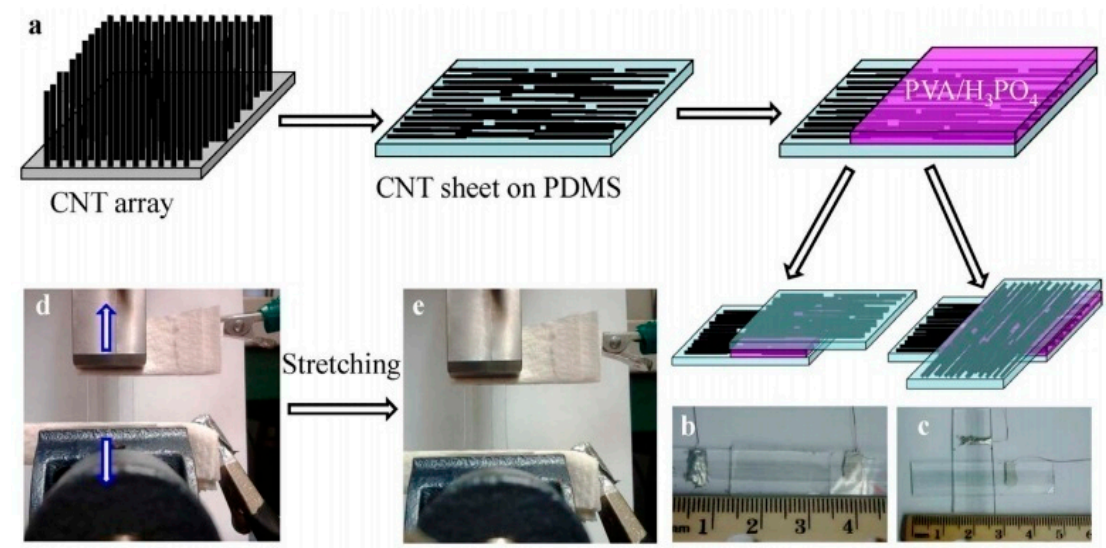

Figure 5. Diagram of the fabrication process for the transparent super capacitors and their optical images. (a) Schematic illustration of the process for fabricating the transparent and stretchable super capacitor. $(\mathbf{b}, \mathbf{c})$ Photographs of super capacitors assembled in the parallel and cross configurations. (d,e) Photographs of a super capacitor before and after stretching [66]. Copyright 2014, Nature Publishing Group.

Meanwhile, graphene also shows great potential in flexible and transparent super capacitor [68-72]. Graphene network is transferred onto a flexible and transparent polymer (e.g., PDMS) substrate. It shows both good optical transparency of $86 \%$ and mechanical flexibility [73]. In order to improve electrochemical properties and transparency of graphene electrode, a new strategy of stacked bilayer graphene and an ultrathin redox-active interlayer is invested. It can be clearly seen in Figure 6 that the electrochemical performance has been absolutely improved by this new strategy. Compare with normal graphene, this kind of super capacitor has almost 20 times at lower scan rates or 10 times at higher scan rates improvement in area-specific capacitance (in Figure 6a). Simultaneously, corresponding to the result in Figure 6a, the area-specific capacitance of the CD curve in Figure $6 \mathrm{~b}$ is also increased. In addition, the super capacitor exhibits superior transparency of $75 \%$ and excellent flexibility [71]. This indicates that this redox-active interlayer is very stable between stacked bilayer graphene. It is of great significance to the generation of novel flexible transparent super capacitor.

(a)

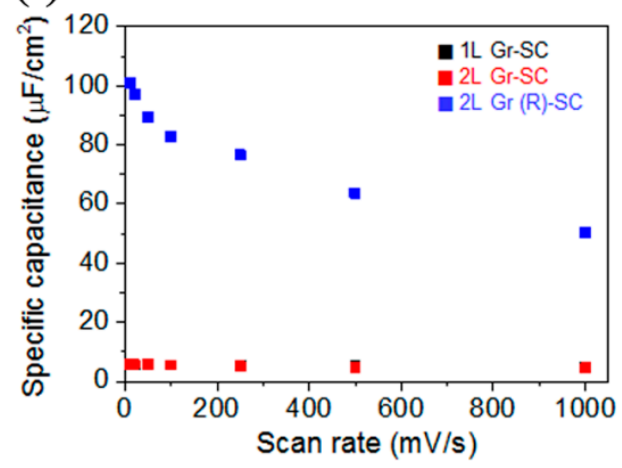

(b)

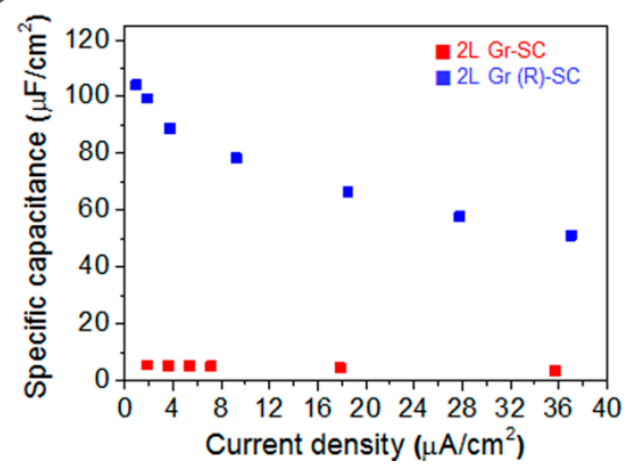

Figure 6. (a) The area-specific capacitances of 1L Gr-SC, 2L Gr-SC and 2L Gr (R)-SC calculated from the CV curves at the indicated scan rates. (b) The area-specific capacitances of 2L Gr-SC and 2L Gr (R)-SC calculated from the CD curves at the indicated current densities [71]. Copyright 2015, American Chemical Society.

Keunsik et al. fabricate the micro-super capacitor by chelating graphene quantum dots with graphene together. They attach graphene quantum dots to finger graphene by simple chemical deposition, and the graphene and graphene quantum dots form chelates through metal ions. The cross patterns of graphene form porous ipG-GQDs films. This kind of film exhibits high transparency of 
$92.97 \%$ at $550 \mathrm{~nm}$, high energy storage of $9.09 \mu \mathrm{F} \mathrm{cm}{ }^{2}$, and high stability even at severe bending angles of 45 degrees and 10,000 cycles. It indicates that the transparent and flexible interdigitated pattern of graphene-graphene quantum dot micro-super capacitor (ipG-GQDs-MSC) has strong potential for industrial integrated power supply [72]. Besides, faraday transition-metal-oxide/hydroxide (TMH) materials are often used to fabricate super capacitor. Na Li et al. realize the transparent micro-structured TMH electrodes formed by graphene enwrapped transition-metal-oxide/hydroxide (TMH) material, thus overcome the difficulties of preparation with the transparent micro-structured TMH electrodes. This microstructure can increase the speed of 3D electron/ion transport pathways, with a high specific capacity of $17.42 \mathrm{mF} \mathrm{cm}^{-2}$ at $0.2 \mathrm{~mA} \mathrm{~cm}^{-2}$ as well as a high capacity retention ( $\left.85.1 \%\right)$ after 20,000 cycles [74]. Based on the above illustration, it can be seen that carbon nanomaterial based electrodes have great potential in achieving transparent and flexible super capacitors.

Although carbon nanomaterials and graphene have broad applications in flexible and transparent super capacitor, they have many assignable drawbacks such as the poor or short cycle life, which makes them less mature in industry. Therefore, many other conductive materials are researched extensively to find out more suitable candidate for flexible and transparent super capacitor. Transition metal oxides have been widely used in the manufacture of super capacitor, with high electrical conductivity and excellent mechanical properties. The flexible and transparent $\mathrm{Co}_{3} \mathrm{O}_{4}$-based super capacitor exhibits superior property than that of carbon-based super capacitor. As shown in Figure 7a, the super capacitor gets a high capacitance of $177 \mathrm{~F} \mathrm{~g}^{-1}$ at a scan rate of $1 \mathrm{mV} \mathrm{s}^{-1}$. Especially, the capacitance retention achieves $100 \%$ after 20,000 cycles and 93\% after 30,000 cycles (as shown in Figure 7b) [75]. Compared with the previously reported carbon-based pseudo capacitor, it has superior performance. It can largely solve the defects of super capacitors with short life. Moreover, an innovative method of laser ablation can synthesize ultrafine $\mathrm{NiCo}_{2} \mathrm{O}_{4}$ nanospheres. The transparent and flexible $\mathrm{NiCo}_{2} \mathrm{O}_{4}$-based device shows the cycling retention of $90.4 \%$ after 10,000 cycles. More importantly, this device gets a typical transmittance of $55 \%$ and shows an excellent mechanical flexibility, which means that transition metal oxides is an ideal active materials for transparent and flexible energy storage devices [76]. In addition, Ag nanowire is belonging to one of the most promising candidates for transparent and stretchable electronics. Compared with typical Ag nanowire device, a modified Ag-Au core-shell nanowire percolation network electrode can greatly improve the electrochemical instability with the stable performance up to 60\% [77].

PANi nanowires-based electrode attracts much attention of researchers due to the high specific capacitance, low monomer cost and relative flexibility [78]. According to the above, graphene is the competitive material candidates of super-capacitor electrodes. Fanhong Chen and co-workers fabricate nanocomposite films of reduced graphene oxide ( $\mathrm{rGO}$ ) and aligned polyaniline (PANI) to integrate the advantages of these two materials. The device shows excellent transparency in Figure 8. The transmittance of film is gradually decrease from top to bottom that $93.67 \%$ for PET / Ag NWs film, 92.96\% for FTCF substrate, $89.67 \%$ for rGO-coated FTCF film (FTCF/rGO), 78.76\% for FTCF/rGO/PANI and $72.92 \%$ for PANI-coated FTCF film (FTCF/PANI) at $550 \mathrm{~nm}$, respectively, as shown in Figure 8a. And the corresponding film form from left to right is shown in Figure $8 \mathrm{~b}$. It can be also known that the FTCF/rGO/PANI nanocomposite film has excellent bendability [79]. The assembled super capacitor exhibits excellent capacitance performance, enhanced transparency and superior flexibility because of the synergistic effects of PANI and graphene, the growing electron transport from graphene and the large surface area from aligned PANI film promoting ion diffusion. This method attempts a wonderful strategy of synergistic effect to promote the development and application of flexible and transparent super capacitor. 

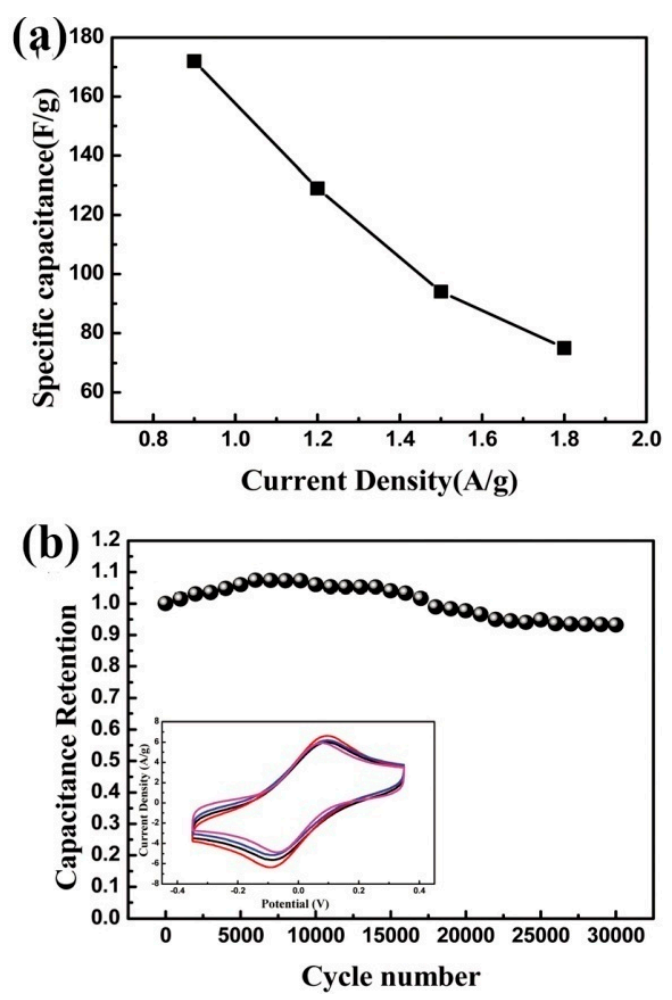

Figure 7. (a) Specific capacitance of the super capacitor at a series of current densities. (b) CV curves of the super capacitor at 10,000, 20,000 and 30,000 cycles, respectively [75]. Copyright 2016, the Royal Society of Chemistry

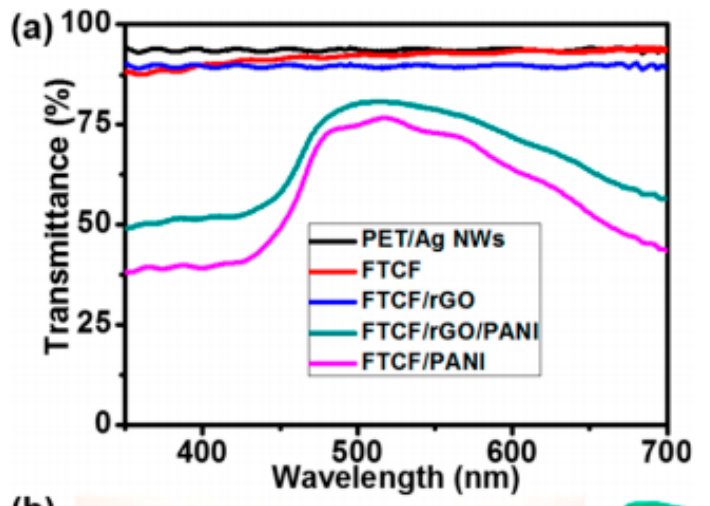

(b)

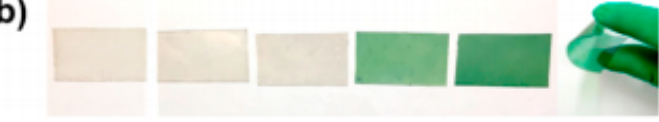

Figure 8. (a) Transparency spectra of PET/Ag NWs film, FTCF substrate, FTCF/rGO, FTCF/rGO/PANI and FTCF/PANI, respectively. (b) The photographs of corresponding film from (left to right) for PET/Ag NWs film, FTCF substrate, FTCF/rGO, FTCF/rGO/PANI, FTCF/PANI and the flexible FTCF/rGO/PANI [79]. Copyright 2017, American Chemical Society

\section{Conclusions}

With the rapid progress of electronic technology, it seems that many researchers are full of beautiful longing for comfortable and multi-function wearable devices. The energy supply equipment is one of the most important problems to be solved. Among the energy storage systems, lithium-ion batteries and super capacitors are important components of the device, integrating transparent and stretchable properties into an energy storage device which restricts the development of these electronic devices is a great challenge. In recent years, great progress has been made in materials exploration, 
structural design, manufacturing methods and integrated assembly of flexible and transparent energy storage devices. Flexible and transparent energy storage devices can be implemented in two directions: New structure design and new material exploration. Herein, the development of flexible and transparent lithium-ion battery and super capacitors has been introduced in the paper. Under persistent efforts, many new materials and new strategies are applied in lithium-ion battery or super capacitor. Carbon nanomaterial like carbon nanotube, carbon nanofiber and graphene and the new design of these materials have been adopted to develop energy storage systems. Carbon nanotube is usually used as supporting part, which can improve the electronic conductivity. But, the electronic property of carbon nanotube is comparatively lower than that of graphene. Moreover, graphene with large specific surface area can effectively alleviate the volume expansion in the process of lithiation, which makes it a promising candidate for future flexible and transparent storage devices. The application of other conductive materials in energy storage devices, such as transition metals and transition-metal-oxide/hydroxide (TMH) material, is also introduced. However, due to various factors, the development of these materials in flexible transparent lithium-ion battery and super capacitor cannot meet the needs of practical applications. Thus, in the future, it is very important and desirable to enhance property of flexibility, transparency and electrochemical of energy storage device. Of course, there are many problems and challenges to realize the practical application of flexible and transparent energy storage devices, such as to explore low-cost material, to improve the cycle stability of flexible devices, to improve the large-scale production technology and so on. That requires researchers to devote more energy to electrode material research, electrode structure design and production process development. On the other hand, we believe that, with the rapid development of science and the continuous efforts of scientific researchers, this kind of energy storage device with high performance and special functions will be realized in the near future, which will greatly improve the quality of our life.

Acknowledgments: The work is supported by the National Natural Science Foundation of China (Grant Nos.: 51473082, 51273096 and 51603109), the program of Introducing Talents to the Universities (111 plan) and the National One-Thousand Foreign Expert Program (No. WQ20123700111), the Natural Science Foundation of Shandong province (No. ZR2017BEM047) and the postdoctoral science foundation of China (No. 2017M610408).

Conflicts of Interest: The authors declare no conflict of interest.

\section{References}

1. Wu, Y.; Wu, H.; Luo, S.; Wang, K.; Zhao, F.; Wei, Y.; Liu, P.; Jiang, K.; Wang, J.; Fan, S. Entrapping electrode materials within ultrathin carbon nanotube network for flexible thin film lithium ion batteries. RSC Adv. 2014, 4, 20010-20016. [CrossRef]

2. Kim, J.-S.; Lee, Y.-H.; Lee, I.; Kim, T.-S.; Ryou, M.-H.; Choi, J.W. Large area multi-stacked lithium-ion batteries for flexible and rollable applications. J. Mater. Chem. A 2014, 2, 10862-10868. [CrossRef]

3. Cao, S.; Feng, X.; Song, Y.; Xue, X.; Liu, H.; Miao, M.; Fang, J.; Shi, L. Integrated fast assembly of free-standing lithium titanate/carbon nanotube/cellulose nanofiber hybrid network film as flexible paper-electrode for lithium-ion batteries. ACS Appl. Mater. Interfaces 2015, 7, 10695-10718. [CrossRef] [PubMed]

4. Ghosh, A.; Manjunatha, R.; Kumar, R.; Mitra, S. A facile bottom-up approach to construct hybrid flexible cathode scaffold for high-performance lithium-sulfur batteries. ACS Appl. Mater. Interfaces 2016, 8, 33775-33785. [CrossRef] [PubMed]

5. Wang, X.; Li, G.; Seo, M.H.; Lui, G.; Hassan, F.M.; Feng, K.; Xiao, X.; Chen, Z. Carbon-coated silicon nanowires on carbon fabric as self-supported electrodes for flexible lithium-ion batteries. ACS Appl. Mater. Interfaces 2017, 9, 9551-9558. [CrossRef] [PubMed]

6. Huang, J.Q.; Xu, Z.L.; Abouali, S.; Garakani, M.A.; Kim, J.K. Porous graphene oxide/carbon nanotube hybrid films as interlayer for lithium-sulfur batteries. Carbon 2016, 99, 624-632. [CrossRef]

7. Wang, K.; Wu, H.; Meng, Y.; Zhang, Y.; Wei, Z. Integrated energy storage and electrochromic function in one flexible device: An energy storage smart window. Energy Environ. Sci. 2012, 5, 8384-8389. [CrossRef] 
8. Niu, Z.; Du, J.; Cao, X.; Sun, Y.; Zhou, W.; Hng, H.H.; Ma, J.; Chen, X.; Xie, S. Electrophoretic build-up of alternately multilayered films and micropatterns based on graphene sheets and nanoparticles and their applications in flexible supercapacitors. Small 2012, 8, 3201-3208. [CrossRef] [PubMed]

9. Rodríguez, J.; Navarrete, E.; Dalchiele, E.A.; Sánchez, L.; Ramos-Barrado, J.R.; Martín, F. Polyvinylpyrrolidone$\mathrm{LiClO}_{4}$ solid polymer electrolyte and its application in transparent thin film supercapacitors. J. Power Sources 2013, 237, 270-276. [CrossRef]

10. Chen, T.; Dai, L. Flexible supercapacitors based on carbon nanomaterials. J. Mater. Chem. A 2014, 2, 10756-10775. [CrossRef]

11. Niu, Z.; Liu, L.; Zhang, L.; Zhou, W.; Chen, X.; Xie, S. Programmable nanocarbon-based architectures for flexible supercapacitors. Adv. Energy Mater. 2015, 5, 1500677-1500696. [CrossRef]

12. Ju, S.; Li, J.; Liu, J.; Chen, P.C.; Ha, Y.G.; Ishikawa, F.; Chang, H.; Zhou, C.; Facchetti, A.; Janes, D.B.; et al. Transparent active matrix organic light-emitting diode displaysdriven by nanowire transistor circuitry. Nano Lett. 2007, 8, 997-1004. [CrossRef] [PubMed]

13. Wang, L.; Yoon, M.H.; Lu, G.; Yang, Y.; Facchetti, A.; Marks, T.J. High-performance transparent inorganic-organic hybrid thin-film n-type transistors. Nat. Mater. 2006, 5, 893-900. [CrossRef] [PubMed]

14. Wang, T.; Guo, Y.; Wan, P.; Zhang, H.; Chen, X.; Sun, X. Flexible transparent electronic gas sensors. Small 2016, 12, 3748-3756. [CrossRef] [PubMed]

15. Choi, I.Y.; Lee, J.; Ahn, H.; Lee, J.; Choi, H.C.; Park, M.J. High-conductivity two-dimensional polyaniline nanosheets developed on ice surfaces. Angew. Chem. Int. Ed. 2015, 54, 10497-10501. [CrossRef] [PubMed]

16. Heo, G.; Pyo, K.H.; Lee, D.H.; Kim, Y.; Kim, J.W. Critical role of diels-adler adducts to realise stretchable transparent electrodes based on silver nanowires and silicone elastomer. Sci. Rep. 2016, 6, 25358-25367. [CrossRef] [PubMed]

17. Pyo, J.B.; Kim, B.S.; Park, H.; Kim, T.A.; Koo, C.M.; Lee, J.; Son, J.G.; Lee, S.S.; Park, J.H. Floating compression of Ag nanowire networks for effective strain release of stretchable transparent electrodes. Nanoscale 2015, 7, 16434-16441. [CrossRef] [PubMed]

18. Yao, B.; Huang, L.; Zhang, J.; Gao, X.; Wu, J.; Cheng, Y.; Xiao, X.; Wang, B.; Li, Y.; Zhou, J. Flexible transparent molybdenum trioxide nanopaper for energy storage. Adv. Mater. 2016, 28, 6353-6358. [CrossRef] [PubMed]

19. Tarascon, J.M.; Armand, M. Issues and Challenges Facing Rechargeable Lithium Batteries. Nature 2001, 414, 359-367. [CrossRef] [PubMed]

20. Etacheri, V.; Marom, R.; Elazari, R.; Salitra, G.; Aurbach, D. Challenges in the development of advanced Li-ion batteries: A review. Energy Environ. Sci. 2011, 4, 3243. [CrossRef]

21. Scrosati, B.; Garche, J. Lithium batteries: Status, prospects and future. J. Power Sources 2010, 195, 2419-2430. [CrossRef]

22. Seung-Min, P.; EunJoo, Y.; Itaru, H. Enhanced cyclic performance and lithium storage capacity of $\mathrm{SnO}_{2}$ /graphene nanoporous electrodes with three-dimensionally delaminated flexible structure. Nano Lett. 2009, 9, 72-75.

23. Hu, L.; Wu, H.; La, M.F.; Yang, Y.; Cui, Y. Thin, flexible secondary Li-ion paper batteries. ACS Nano 2010, 4 , 5843-5848. [CrossRef] [PubMed]

24. Zhou, G.; Li, F.; Cheng, H.-M. Progress in flexible lithium batteries and future prospects. Energy Environ. Sci. 2014, 7, 1307-1338. [CrossRef]

25. Wang, C.; Cao, Y.; Luo, Z.; Li, G.; Xu, W.; Xiong, C.; He, G.; Wang, Y.; Li, S.; Liu, H. Flexible potassium avnadate nanowires on Ti fabric as a binder-free cathode for high-performance advanced lithium-ion battery. Chem. Eng. J. 2016, 307, 382-388. [CrossRef]

26. Park, M.; Cha, H.; Lee, Y.; Hong, J.; Kim, S.Y.; Cho, J. Postpatterned electrodes for flexible node-type lithium-ion batteries. Adv. Mater. 2017, 29, 1605773-1605780. [CrossRef] [PubMed]

27. Liu, J.; Song, K.; van Aken, P.A.; Maier, J.; Yu, Y. Self-supported $\mathrm{Li}_{4} \mathrm{Ti}_{5} \mathrm{O}_{12}-\mathrm{C}$ nanotube arrays as high-rate and long-life anode materials for flexible Li-ion batteries. Nano Lett. 2014, 14, 2597-2603. [CrossRef] [PubMed]

28. Chen, X.; Tang, H.; Huang, Z.; Zhou, J.; Ren, X.; Huang, K.; Qi, X.; Zhong, J. Flexible bismuth selenide/graphene composite paper for lithium-ion batteries. Ceram. Int. 2016, 43, 1437-1442. [CrossRef]

29. Li, N.; Chena, Z.; Rena, W.; Lia, F.; Chenga, H.-M. Flexible graphene-based lithium ion batteries with ultrafast charge and discharge rates. Proc. Natl. Acad. Sci. USA 2012, 109, 17360-17365. [CrossRef] [PubMed] 
30. Mo, R.; Rooney, D.; Sun, K.; Yang, H.Y. 3D nitrogen-doped graphene foam with encapsulated germanium/nitrogen-doped graphene yolk-shell nanoarchitecture for high-performance flexible Li-ion battery. Nat. Commun. 2017, 8, 13949-13958. [CrossRef] [PubMed]

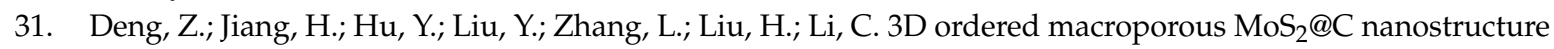
for flexible Li-ion batteries. Adv. Mater. 2017, 29, 1603020-1603026. [CrossRef] [PubMed]

32. Yoon, J.; Baca, A.J.; Park, S.I.; Elvikis, P.; Geddes, J.B., 3rd; Li, L.; Kim, R.H.; Xiao, J.; Wang, S.; Kim, T.H.; et al. Ultrathin silicon solar microcells for semitransparent, mechanically flexible and microconcentrator module designs. Nat. Mater. 2008, 7, 907-915. [CrossRef] [PubMed]

33. Martín, F.; Navarrete, E.; Morales, J.; Roldán, C.; Ramos-Barrado, J.R.; Sánchez, L. High-energy, efficient and transparent electrode for lithium batteries. J. Mater. Chem. 2010, 20, 2847-2852. [CrossRef]

34. Jung, S.; Lee, S.; Song, M.; Kim, D.-G.; You, D.S.; Kim, J.-K.; Kim, C.S.; Kim, T.-M.; Kim, K.-H.; Kim, J.-J.; et al. Extremely Flexible Transparent Conducting Electrodes for Organic Devices. Adv. Energy Mater. 2014, 4, 1300474. [CrossRef]

35. Yang, Y.; Jeong, S.; Hu, L.; Wu, H.; Lee, S.W.; Cui, Y. Transparent lithium-ion batteries. Proc. Natl. Acad. Sci. USA 2011, 108, 13013-13018. [CrossRef] [PubMed]

36. Gittleson, F.S.; Hwang, D.; Ryu, W.H.; Hashmi, S.M.; Hwang, J.; Goh, T.; Taylor, A.D. Ultrathin nanotube/nanowire electrodes by spin-spray layer-by-layer assembly: A concept for transparent energy storage. ACS Nano 2015, 9, 10005-10017. [CrossRef] [PubMed]

37. Niu, Z.; Luan, P.; Shao, Q.; Dong, H.; Li, J.; Chen, J.; Zhao, D.; Cai, L.; Zhou, W.; Chen, X. A “skeleton/skin” strategy for preparing ultrathin free-standing single-walled carbon nanotube/polyaniline films for high performance supercapacitor electrodes. Energy Environ. Sci. 2012, 5, 8726-8733. [CrossRef]

38. Cong, H.P.; Ren, X.C.; Wang, P.; Yu, S.H. Flexible graphene-polyaniline composite paper for high-performance supercapacitor. Energy Environ. Sci. 2013, 6, 1185-1191. [CrossRef]

39. Liu, L.; Niu, Z.; Zhang, L.; Zhou, W.; Chen, X.; Xie, S. Nanostructured graphene composite papers for highly flexible and foldable supercapacitors. Adv. Mater. 2014, 26, 4855-4862. [CrossRef] [PubMed]

40. Xu, J.; Yang, C.; Xue, Y.; Wang, C.; Cao, J.; Chen, Z. Facile synthesis of novel metal-organic nickel hydroxide nanorods for high performance supercapacitor. Electrochim. Acta 2016, 211, 595-602. [CrossRef]

41. Mendoza-Sanchez, B.; Gogotsi, Y. Synthesis of two-dimensional materials for capacitive energy storage. Adv. Mater. 2016, 28, 6104-6135. [CrossRef] [PubMed]

42. Lv, T.; Yao, Y.; Li, N.; Chen, T. Highly stretchable supercapacitors based on aligned carbon nanotube/ molybdenum disulfide composites. Angew. Chem. 2016, 128, 9191-9195. [CrossRef] [PubMed]

43. Peng, L.; Xu, P.; Liu, B.; Wu, C.; Xie, Y.; Yu, G. Ultrathin two-dimensional $\mathrm{MnO}_{2}$ /graphene hybrid nanostructures for high-performance, flexible planar supercapacitors. Nano Lett. 2013, 13, 2151-2157. [CrossRef] [PubMed]

44. Qi, D.; Liu, Z.; Liu, Y.; Leow, W.R.; Zhu, B.; Yang, H.; Yu, J.; Wang, W.; Wang, H.; Yin, S. Suspended wavy graphene microribbons for highly stretchable microsupercapacitors. Adv. Mater. 2015, 27, 5559-5566. [CrossRef] [PubMed]

45. Li, X.; Zhang, C.; Xin, S.; Yang, Z.; Li, Y.; Zhang, D.; Yao, P. A facile synthesis of $\mathrm{MoS}_{2} /$ reduced graphene oxide@polyaniline for high-performance supercapacitors. ACS Appl. Mater. Interfaces 2016, 8, 21373-21380. [CrossRef] [PubMed]

46. Kang, Y.J.; Chun, S.J.; Lee, S.S.; Kim, B.Y.; Kim, J.H.; Chung, H.; Lee, S.Y.; Kim, W. All-solid-state flexible supercapacitors fabricated with bacterial nanocellulose papers, carbon nanotubes, and triblock-copolymer ion gels. ACS Nano 2012, 6, 6400-6406. [CrossRef] [PubMed]

47. Hu, L.; Pasta, M.; Mantia, F.L.; Cui, L.; Jeong, S.; Deshazer, H.D.; Choi, J.W.; Han, S.M.; Cui, Y. Stretchable, porous, and conductive energy textiles. Nano Lett. 2010, 10, 708-714. [CrossRef] [PubMed]

48. Liu, Y.; Zhou, J.; Chen, L.; Zhang, P.; Fu, W.; Zhao, H.; Ma, Y.; Pan, X.; Zhang, Z.; Han, W. Highly flexible freestanding porous carbon nanofibers for electrodes materials of high-performance all-carbon supercapacitors. ACS Appl. Mater. Interfaces 2015, 7, 23515-23520. [CrossRef] [PubMed]

49. Rodríguez-Moreno, J.; Navarrete-Astorga, E.; Dalchiele, E.A.; Schrebler, R.; Ramos-Barrado, J.R.; Martín, F. Vertically aligned ZnO@CuS@PEDOTcore@shellnanorod arrays decorated with $\mathrm{MnO}_{2}$ nanoparticles for a high-performance and semi-transparent supercapacitor electrode. Chem. Commun. 2014, 50, 5652-5655. [CrossRef] [PubMed] 
50. Niu, Z.; Zhou, W.; Chen, J.; Feng, G.; Hong, L.; Hu, Y.; Ma, W.; Dong, H.; Li, J.; Xie, S. A repeated halving approach to fabricate ultrathin single-walled carbon nanotube films for transparent supercapacitors. Small 2013, 9, 518-524. [CrossRef] [PubMed]

51. Kholmanov, I.N.; Domingues, S.H.; Chou, H.; Wang, X.; Tan, C.; Kim, J.Y.; Li, H.; Piner, R.; Zarbin, A.J.; Ruoff, R.S. Reduced graphene oxide/copper nanowire hybrid films as high-performance transparent electrodes. ACS Nano 2013, 7, 1811-1816. [CrossRef] [PubMed]

52. Yu, A.; Roes, I.; Davies, A.; Chen, Z. Ultrathin, transparent, and flexible graphene films for supercapacitor application. Appl. Phys. Lett. 2010, 96, 253105. [CrossRef]

53. Hu, Y.; Zhu, H.; Wang, J.; Chen, Z. Synthesis of layered birnessite-type manganese oxide thin films on plastic substrates by chemical bath deposition for flexible transparent supercapacitors. J. Alloys Compd. 2011, 509, 10234-10240. [CrossRef]

54. Gao, K.; Shao, Z.; Wu, X.; Wang, X.; Zhang, Y.; Wang, W.; Wang, F. Paper-based transparent flexible thin film supercapacitors. Nanoscale 2013, 5, 5307-5311. [CrossRef] [PubMed]

55. Qiu, T.; Luo, B.; Giersig, M.; Akinoglu, E.M.; Hao, L.; Wang, X.; Shi, L.; Jin, M.; Zhi, L. Au@MnO 2 core-shell nanomesh electrodes for transparent flexible supercapacitors. Small 2014, 10, 4136-4141. [PubMed]

56. Cai, G.; Darmawan, P.; Cui, M.; Wang, J.; Chen, J.; Magdassi, S.; Lee, P.S. Highly stable transparent conductive silver grid/PEDOT:PSS electrodes for integrated bifunctional flexible electrochromic supercapacitors. Adv. Energy Mater. 2016, 6, 1501882-1501889. [CrossRef]

57. Mukesh, C.; Gupta, R.; Srivastava, D.N.; Nataraj, S.K.; Prasad, K. Preparation of a natural deep eutectic solvent mediated self polymerized highly flexible transparent gel having super capacitive behaviour. RSC Adv. 2016, 6, 28586-28592. [CrossRef]

58. Ge, J.; Cheng, G.; Chen, L. Transparent and flexible electrodes and supercapacitors using polyaniline/ single-walled carbon nanotube composite thin films. Nanoscale 2011, 3, 3084-3088. [CrossRef] [PubMed]

59. Peng, L.; Feng, Y.; Lv, P.; Lei, D.; Shen, Y.; Li, Y.; Feng, W. Transparent, conductive, and flexible multiwalled carbon nanotube/graphene hybrid electrodes with two three-dimensional microstructures. J. Phys. Chem. C 2012, 116, 4970-4978. [CrossRef]

60. Jung, H.Y.; Karimi, M.B.; Hahm, M.G.; Ajayan, P.M.; Jung, Y.J. Transparent, flexible supercapacitors from nano-engineered carbon films. Sci. Rep. 2012, 2, 773-778. [CrossRef] [PubMed]

61. Kanninen, P.; Luong, N.D.; Anoshkin, I.V.; Tsapenko, A.; Seppala, J.; Nasibulin, A.G.; Kallio, T. Transparent and flexible high-performance supercapacitors based on single-walled carbon nanotube films. Nanotechnology 2016, 27, 235403-235409. [CrossRef] [PubMed]

62. Sansom, E.B.; Rinderknecht, D.; Gharib, M. Controlled partial embedding of carbon nanotubes within flexible transparent layers. Nanotechnology 2008, 19, 035302. [CrossRef] [PubMed]

63. Li, Z.; Jia, Y.; Wei, J.; Wang, K.; Shu, Q.; Gui, X.; Zhu, H.; Cao, A.; Wu, D. Large area, highly transparent carbon nanotube spiderwebs for energy harvesting. J. Mater. Chem. 2010, 20, 7236-7240. [CrossRef]

64. Lin, H.; Li, L.; Ren, J.; Cai, Z.; Qiu, L.; Yang, Z.; Peng, H. Conducting polymer composite film incorporated with aligned carbon nanotubes for transparent, flexible and efficient supercapacitor. Sci. Rep. 2013, 3, 1353. [CrossRef] [PubMed]

65. Yuksel, R.; Sarioba, Z.; Cirpan, A.; Hiralal, P.; Unalan, H.E. Transparent and flexible supercapacitors with single walled carbon nanotube thin film electrodes. ACS Appl. Mater. Interfaces 2014, 6, 15434-15439. [CrossRef] [PubMed]

66. Chen, T.; Peng, H.; Durstock, M.; Dai, L. High-performance transparent and stretchable all-solid supercapacitors based on highly aligned carbon nanotube sheets. Sci. Rep. 2014, 4, 3612-3618. [CrossRef] [PubMed]

67. Wang, T.; Zhao, D.; Alvarez, N.; Shanov, V.N.; Heineman, W.R. Optically transparent carbon nanotube film electrode for thin layer spectroelectrochemistry. Anal. Chem. 2015, 87, 9687-9695. [CrossRef] [PubMed]

68. Xu, P.; Kang, J.; Choi, J.B.; Suhr, J.; Yu, J.; Li, F.; Byun, J.H.; Kim, B.S.; Chou, T.W. Laminated ultrathin chemical vapor deposition graphene films based stretchable and transparent high-rate supercapacitor. ACS Nano 2014, 8, 9437-9445. [CrossRef] [PubMed]

69. Ashis, K.S.; Jong-Dal, H. Flexible and transparent plastic electrodes composed of reduced graphene oxide-polyaniline films for supercapacitor application. Bull. Korean Chem. Soc 2014, 35, 1799-1805.

70. Chen, T.; Xue, Y.; Roy, A.K.; Dai, L. Transparent and stretchable high-performance supercapacitors based on wrinkled graphene electrodes. Acs Nano 2014, 8, 1039-1046. [CrossRef] [PubMed] 
71. Jo, K.; Lee, S.; Kim, S.M.; In, J.B.; Lee, S.M.; Kim, J.H.; Lee, H.J.; Kim, K.S. Stacked bilayer graphene and redox-active interlayer for transparent and flexible high-performance supercapacitors. Chem. Mater. 2015, 27, 3621-3627. [CrossRef]

72. Lee, K.; Lee, H.; Shin, Y.; Yoon, Y.; Kim, D.; Lee, H. Highly transparent and flexible supercapacitors using graphene-graphene quantum dots chelate. Nano Energy 2016, 26, 746-754. [CrossRef]

73. Xueliu, F.; Tao, C.; Liming, D. Graphene networks for high-performance flexible and transparent supercapacitors. RSC Adv. 2014, 4, 36996-37002.

74. Li, N.; Huang, X.; Zhang, H. High energy density transparent and flexible asymmetric supercapacitor based on a transparent metal hydroxides@graphene micro-structured film via a scalable gas-liquid diffusion method. J. Alloys Compd. 2017, 712, 194-203. [CrossRef]

75. Liu, X.Y.; Gao, Y.Q.; Yang, G.W. A flexible, transparent and super-long-life supercapacitor based on ultrafine $\mathrm{Co}_{3} \mathrm{O}_{4}$ nanocrystal electrodes. Nanoscale 2016, 8, 4227-4235. [CrossRef] [PubMed]

76. Liu, X.; Wang, J.; Yang, G. Transparent, flexible, and high-performance supercapacitor based on ultrafine nickel cobaltite nanospheres. Appl. Phys. A 2017, 123, 997-1007. [CrossRef]

77. Lee, H.; Hong, S.; Lee, J.; Suh, Y.D.; Kwon, J.; Moon, H.; Kim, H.; Yeo, J.; Ko, S.H. Highly stretchable and transparent supercapacitor by Ag-Au core-shell nanowire network with high electrochemical stability. ACS Appl. Mater. Interfaces 2016, 8, 15449-15458. [CrossRef] [PubMed]

78. Devarayan, K.; Lei, D.; Kim, H.-Y.; Kim, B.-S. Flexible transparent electrode based on PANi nanowire/nylon nanofiber reinforced cellulose acetate thin film as supercapacitor. Chem. Eng. J. 2015, 273, 603-609. [CrossRef]

79. Chen, F.; Wan, P.; Xu, H.; Sun, X. Flexible transparent supercapacitors based on hierarchical nanocomposite films. ACS Appl. Mater. Interfaces 2017, 9, 17865-17871. [CrossRef] [PubMed]

(C) 2018 by the authors. Licensee MDPI, Basel, Switzerland. This article is an open access article distributed under the terms and conditions of the Creative Commons Attribution (CC BY) license (http:/ / creativecommons.org/licenses/by/4.0/). 